\title{
EchoGéo
}

27 | 2014

Structures et armatures urbaines

\section{Des villes aux territoires}

Jean-Louis Chaléard

\section{(2) OpenEdition}

Journals

Édition électronique

URL : https://journals.openedition.org/echogeo/13806

DOI : 10.4000/echogeo.13806

ISSN : 1963-1197

\section{Éditeur}

Pôle de recherche pour l'organisation et la diffusion de l'information géographique (CNRS UMR 8586)

\section{Référence électronique}

Jean-Louis Chaléard, «Des villes aux territoires », EchoGéo [En ligne], 27 | 2014, mis en ligne le 02 avril 2014, consulté le 10 août 2021. URL : http://journals.openedition.org/echogeo/13806 ; DOI : https:// doi.org/10.4000/echogeo.13806

Ce document a été généré automatiquement le 10 août 2021.

EchoGéo est mis à disposition selon les termes de la licence Creative Commons Attribution - Pas d'Utilisation Commerciale - Pas de Modification 4.0 International (CC BY-NC-ND) 


\title{
Des villes aux territoires
}

\author{
Jean-Louis Chaléard
}

1 La nouvelle livraison d'EchoGéo s'organise auteur de thèmes et d'approches variés : un dossier consacré aux villes et aux structures urbaines, un autre sur les métiers de l'environnement, des textes sur des élections, une frontière ... Dans tous les cas, c'est bien de géographie qu'il s'agit, même si les approches, les emprunts ou les liens avec d'autres disciplines (que ce soit la géologie, l'informatique, l'histoire, ...) conduisent à enrichir les questionnements, les outils, les résultats.

2 Le dossier de la rubrique Sur le champ est consacré aux «structures et armatures urbaines ». Les articles qui le composent portent sur des études de cas variés, allant du micro au macro. À juste titre C. Vandermotten, dans son introduction, inscrit dans une perspective historique, sur quatre ou cinq décennies, les approches comme les sujets abordés, et resitue dans un cadre plus large, européen et mondial, les textes portant sur des analyses en Chine et en France. L'analyse qu'il propose va ainsi au-delà de la simple lecture des cinq articles du dossier, abordant des questions anciennes, actuelles, renouvelées: le maillage urbain, la périurbanisation, les infrastructures, la métropolisation, etc.

3 La Chine se singularise fortement par rapport aux pays européens par la rapidité de sa croissance urbaine. Dans la province du Zhejiang, le dynamisme des petites villes y est un phénomène majeur (que l'on retrouve d'ailleurs dans d'autres pays émergents). Les villes encadrent des territoires densément peuplés où les relations de tous ordres sont intenses. La figure de la desakota (pour reprendre l'expression de Mc Gee) convoquée par l'auteur, S. Milhaud, rappelle l'intensité des liens entre villes et campagnes, autour d'une ou de métropoles en Asie du Sud, du Sud-est et de l'Est, interrogeant à la fois les structures urbaines, les organisations régionales et le contenu des périphéries « ruralourbaines ». Dans un tout autre contexte, J. Gingembre et J. Baude abordent les mobilités domicile-travail dans les réseaux d'agglomération en France: ils présentent l'autonomisation des systèmes urbains régionaux, hors la métropole parisienne, qui facilite les mobilités de main-d'œuvre et les potentialités d'emplois, particulièrement des cadres. À l'échelle de chaque agglomération urbaine, les phénomènes de périurbanisation ont pris une dimension et un contenu nouveaux. À partir de l'analyse 
de l'ouest francilien, M. Berger, C. Aragau et L. Rougé s'interrogent sur la « maturité des espaces périurbains" qui voient se développer des mobilités de proximité et une volonté d'ancrage dans les communes de résidence, remettant en cause la vision d'un périurbain dominé de façon exclusive par les navettes résidence-travail dans le centre pourvoyeur d'emplois. L'article de K. E. Demailly sur « les jardins partagés franciliens » renvoie aux idéologies et aux actions visant à développer une présence végétale en ville, et met en évidence, à travers la question de la participation citoyenne, l'évolution des gouvernances. Dans le même ordre d'idée, la notion de "ville créative " qu'illustre le texte de $\mathrm{B}$. Lebeau à partir d'une initiative en banlieue, révèle l'écart qui peut exister entre l'espoir suscité par des projets de réintégration fonctionnelle et sociale des quartiers pauvres et la logique des fonctionnements socio-économiques dominants.

4 Ainsi, ces textes nous renvoient l'image de systèmes urbains en mutation où les logiques de déplacement et les modes de gouvernance évoluent. Les vieilles images des couronnes métropolitaines comme des espaces de résidence et de navettes domicilestravail ne sont pas gommées, mais l'extension de certains trajets, la diversification sociale et générationnelle des périurbains, l'évolution des comportements, les initiatives de tous ordres construisent l'image de périphéries métropolitaines dynamiques, foyers d'innovations. Toutefois, face aux multiples projets qui se veulent "créatifs ", C. Vandermotten rappelle que si les classes moyennes demandent des espaces de participation, les décisions restent en fin de compte aux autorités politiques.

5 La rubrique Sur le métier est consacrée à l'environnement et à la géomatique, sujets déjà abordés plusieurs fois, de différentes façons, dans notre revue. Ici le débat tourne autour de la formation et des emplois. Les cinq auteurs du dossier soulignent l'intérêt d'associer les deux domaines. Les questions environnementales ont pris une place considérable dans notre société, que ce soit les pollutions, les catastrophes naturelles, les dégradations diverses. La géomatique est devenue un outil indispensable à la compréhension, la gestion et le management de l'environnement. Elle favorise une réponse aux incertitudes et aux enjeux environnementaux, aux évolutions sociales, aux contraintes juridiques et économiques. Des formations pluridisciplinaires originales, associant géomatique et environnement, se sont ainsi développées. Les auteurs interrogent alors cinq professionnels qui travaillent dans l'environnement et se servent de la géomatique: un consultant chez Bureau Veritas (leader mondial en Test/ Inspection/Certification), une doctorante, un technicien d'étude SIG chez SYSTRA (leader de l'ingénierie de transports publics), une chargée de mission chez ETD (bureau d'étude indépendant), une chargée de mission au sein d'une communauté de communes. La diversité des débouchés et l'intérêt d'une formation en environnement et géomatique transparaissent derrière les témoignages, même si les compétences techniques, en SIG notamment, ne sont pas toujours reconnues par les statuts de la fonction publique territoriale, débouché pourtant non négligeable.

6 La rubrique Sur le vif offre un nouvel article sur la géographie électorale et sur la Côte d'Ivoire. C. Bouquet et I. Kassi-Djodjo tirent les enseignements des élections locales (municipales et régionales) qui ont eu lieu dans le calme en avril 2013, après les législatives de décembre 2011. Ils soulignent les nombreuses faiblesses du processus électoral, le boycott du FPI (parti de l'ancien président L. Gbagbo). Certes les enjeux étaient minces car la décentralisation est encore largement virtuelle. Certes la Cote d'Ivoire n'est ni le Mali ni la Centrafrique. Mais les élections de 2013 montrent que le 
chemin vers la paix et la stabilité intérieure est encore long, alors que celles-ci constituent la première condition pour tout développement économique et social.

7 Dans la rubrique Sur l'écrit, F. Ferretti analyse le livre de l'historien C. Romani sur la construction géo-historique de la frontière entre Brésil et Guyane française, à partir du rôle joué par des géographes français (notamment $\mathrm{H}$. Coudreau, É. Reclus et P. Vidal de la Blache), qui sont intervenus à partir de positions très différentes. Comme dans la rubrique Sur le vif, on touche là à des questions de géographie politique et de géopolitique qui ne sont jamais très loin des préoccupations des géographes, dès qu'ils s'intéressent aux territoires. 